\title{
Estonia and Poland: \\ Creativity and Tradition in Cultural Communication \\ Volume 1: Jokes and Their Relations \\ Edited by L. Laineste, D. Brzozowska, W. Chłopicki, \\ Tartu: ELM Scholarly Press, Tartu 2012, pp. 284
}

The two-volume book titled Estonia and Poland: Creativity and Tradition in Cultural Communication is a collection of articles, which were written as a result of a three-year bilateral project of Estonian and Polish scholars, supported by the Estonian and Polish Academies of Sciences. The editors of the book, Liisi Laineste (Estonian Literary Museum), Dorota Brzozowska (Uniwersytet Opolski) and Władysław Chłopicki (Uniwersytet Jagielloński), are also the coordinators of the project.

Thanks to the cooperation the scientists participated in many conferences, which enabled them to learn more about their cultures. As observed in Foreword, due to the influence of various factors the traditions of Estonians' and Poles' cultural communication is "partly common and partly different" (p. 4). Therefore, it was worth comparing how much they share. Volume one, which will be reviewed, is devoted to jokes and related forms, while the second one focuses on identity.

The book titled Jokes and their relations is composed of eight Estonian and eight Polish papers, which form parallel sets. As for the subjects analysed, the whole volume can be divided into two parts. The first one contains texts whose authors discuss mainly traditional genres, whereas the second deals with "experimental boundaries of the genres" (p. 4-5), such as stand-up and demotivators. Such an approach allows for providing a wide-spectrum picture of various aspects of humour in a cross-cultural perspective. 
The volume starts with two texts discussing Estonian and Polish tripartite jokes, i.e. the ones in which three characters are featured: Arvo Krikmann's article titled Estonian three nation jokes (1964-2012) (pp. 7-20) and Dorota Brzozowska's paper Three characters in Polish jokes (pp. 21-32). Krikmann presents an overview of Estonian three nation jokes from Soviet time, 1990s and present time, analysing changes which occurred in the joke type in the periods considered. Three positions of the characters, who "bear different 'pragmatic load"' (p. 16), i.e. initialisers, follow-uppers and punch-line makers, are discussed in detail and a list of top ten joke plots are given. Brzozowska's aim is to analyse stereotypes present in Polish jokes about three characters and to show how Polish jokes of this kind have transformed from ethnic jokes into jokes about professions. The universal and culture specific character of such jokes is discussed. The author analyses the historical contexts and the role of Poles' neighbours, the Russians and the German, in Polish culture. The stereotypes of the two nations are compared with those of other nations, for instance, Americans. It is done in order to determine if and how ethnic stereotypes function in contemporary jokes. The author concludes that "national stereotypes are not present so visibly in everyday jokes any longer" (p. 31), as the jokes at issue are becoming more ethnically neutral. Moreover, more nationalities appear and they tend to be represented by male characters.

Two papers discuss the social aspect of jokes, mainly woman and family in Estonian and Polish jokelore. Liisi Laineste in her paper Women in Estonian jokes (pp. 33-52) analyses a rich collection of 1869 jokes in which women are mentioned or present from 1960s to 2010. Due to the fact that joke-telling has been mostly a male practice the gender stereotypes are more aggressive and misogynistic. The author also pays attention to political undertones of the Soviet jokes. The article presents the change of the context and the characteristics of the targets in socialism and post-socialism. Thanks to the analysis, it is possible to show how the perception of gender roles is reflected in jokelore. The article titled Family in Polish jokes by Dorota Brzozowska (pp. 53-72) contains the discussion of the image of family in post-socialist Polish jokes. The research material comprises 600 jokes from the period from the late 1990s up to now, taken from books, booklets, newspapers and the Internet. As the author points out, there is no special kind of family joke in Polish culture. The analysis proves the existence of stable targets, for example, aggressive 
mothers-in-law or adulterous wives. The reluctance to create new targets is observed. Therefore, the conclusion can be drawn that Polish family jokes do not refer to current problems and phenomena, as they remain mostly traditional.

The focal issue of another pair of papers is the specifics of Estonian and Polish stand-up comedy. The first article, Stand-up in Estonia: From Soviet estrada to Comedy Estonia, written by Liisi Laineste (pp. 73-90), describes its Estonian realisation on the background of the local history of the genre. The aim of the author is to show how the cultural context as well as the performer and the audience interaction function in terms of gaining popularity. Two periods are analysed: the Soviet time and the present time, with a special focus on the topics and targets. In the former, estrada performances were popular with audience, since they commented on the regime and everyday life of people in a subtle way. Comedy Estonia, following the Anglo-American tradition of stand-up, also achieved popularity with Estonian audience with some established topics, however, it should be noticed that those differ remarkably from those of estrada performances. By conducting a historically oriented analysis the author presents how the traditions have been adopted in a way which allows for the foreign element functioning as an aspect of collective identity. Władysław Chłopicki, the author of the paper titled Stand-up tragedy in Poland? (pp. 90-110), presents the cabaret tradition of Polish comedy and analyses Polish stand-up forms of the last 20 years. The first part is of importance, since the topics not present in the old form, for instance, explicit sex references, are covered in the new one. He discusses the characteristics of stand-up, such as "immediacy, playing cultural and linguistic kinship with the audience, impersonations, "shifting consensus", seeming spontaneity, and occasional self-depreciation" (p. 91). Two Polish shows Na stojaka ('While standing') and Zabij mnie śmiechem ('Kill me with laughter') are presented. As the author observes, the stand-up is not widely popular, since Polish audiences expect the show to be first of all funny, with authentic coming second. He concludes that however the new form is slowly becoming more popular, "the strongly established cabaret tradition has clearly been winning in Poland over recently imported stand-up" (p. 108).

Political jokes are the subject of two papers. The first one, Some aspects of telling political jokes in Soviet Estonia by Martin Rebane (pp. 111-116), discusses the reasons for telling Soviet jokes. The author conducted five 
qualitative open interviews for the pilot study to determine when and why such jokes are told. This study of preliminary character is going to be developed in his further research, which will "take social stratification into account" (p. 115). Marcin Poprawa's contribution titled Polish political humour. An outline of the phenomenon (pp. 117-138) contains a presentation of the most important issues regarding the contemporary Polish political humour. The paper aims at discussing theoretical aspects and at comparing modern Polish political humour with that of the Polish People's Republic (PRL). The article deals mostly with politicians' amusing statements, which gained the status of winged words and were used in various texts. The author presents various linguistic devices which are active in situation-oriented humour (p. 131-133). He concludes that such units are very attractive in communication, since they are communicatively versatile and have connotative and ludic potential.

The phenomenon of political humour is also dealt with in the paper Political correctness and political humour in Soviet Estonia and beyond by Maarja Lōhmus (pp. 139-158). The subject is viewed from the point of view of censorship: the history of censorship in Soviet Estonia is discussed with a focal issue on the regulations regarding the content of humourous texts and images from the pre-1990s period. As the author observes, the Estonian media communication was influenced by two spheres: the official institutional and the unofficial. In the Soviet time humour and ambiguity were not allowed, as the public sphere was under political censorship. Then, until the late 1980s the reflexive attitude was more visible, which was reflected in the increase of number of humorous texts and their widespreadness. After 1987 humour started to perform new functions, such as being a means of de-Sovietisation. It can be concluded that "the presence of humour in journalism is an indicator of emotions in public sphere". The second paper which discusses censorship is Censorship in the People's Republic of Poland by Gawel Strządała (pp. 159-170). The focal issue of the article is the censorship in the communist Poland. The functions of the office of censorship is presented. The author also pays attention to other more unofficial forms of influence on the authors who worked for public publishing houses. Furthermore, he analyses the role of the underground publications, noticing that underground publishers after 1970 played an important role in the creation of opposition in Poland during the period of Communism. 
Visual humour is discussed by the authors of two papers. Anneli Baran in her paper titled Visual humour on the Internet (pp. 171-186) focuses on the humorous pictorial representation on the Internet. The author draws attention to blending of written and spoken language in modern communication, which is a very important phenomenon in a linguocultural perspective. This tendency can be observed in, for instance, various forms of on-line communication. The focal issue of the paper is "a subgenre of Internet memes - demotivational posters or manipulated photos which contain figurative expressions" (p. 171). In the new contexts such language units of metaphoric character are used in a different way from the traditional one. Thanks to the iconic motivation of the units they can be exploited as a means of visualisation. Such use is them is illustrated with well-chosen and interesting examples. The author concludes that the visuality is gaining importance as a result of the influence of the Internet, so "more attention should be paid to the so-called new type of contextualisation taking place in the virtual reality" (p. 185). The other paper dealing with visual aspects is titled Pictorial representation of idioms in Internet humour (pp. 187-203). It was written by Tomasz Piekot who discusses visualising idiomatic expressions in Internet humour. His article is based on empirical studies conducted on selected demotivators which contain idioms. The units at issue undergo various visual transformations, which may influence their structure or their metaphoric meaning. In the former case the visualisation is literal, while in the latter - figurative. The author draws attention to the fact that idioms are not so frequently used in Internet humour, since the messages of demotivating character containing them amount to $1,5 \%$ of the total number of Polish demotivators. In conclusion, he emphasizes the need for further research on visual carriers of figurative meaning on the Internet.

Another issue discussed in the volume is the phenomenon of aggressiveness on the Internet. The article titled Verbal expressions of aggressiveness on the Estonian Internet by Liisi Laineste (pp. 205-220) discusses "the nature and role of online aggression in larger scale societal tensions and its interactions with the use of humour" (p. 205), analysing how aggression is expressed in various on-line contexts. The author focuses on anonymous comments, thematic forums and social networking media and blogs from the material collected from 2000 to 2007 for the needs of a research study coordinated by the Ministry of Justice in Estonia. The sources were chosen so that it could be determined how anonymity in- 
fluences Internet users' comments, including aggressiveness. The paper contains a general presentation of the phenomenon and it discusses how humour functions in Internet flaming. Related issues are also discussed by Anna Tereszkiewicz. In her paper titled Do Polish flame? Aggressiveness on Polish discussion groups and social networking sites (pp. 221-236) she discusses the reflection of this phenomenon in Internet users' language, with a focus on expressions of aggression, hostility and criticism. The material selected for the analysis comes from forums and social media. In particular, the author concentrates on open anonymous forums, sign-in forums and social networking media, so important in modern communication. Moreover, the relation between aggression and irony in language is presented. In conclusion, the author stresses that the nature of online aggressiveness is complex due to many factors.

Humour in grafitti is also one of the issues discussed in the reviewed volume. The paper "In graffiti veritas": A paremic glance at graffiti in Tartu by Piret Voolaid (pp. 237-268) presents how fixed expressions are used in the public space in Tartu, i.e. those areas which can be accessed freely, such as stations, shopping centres etc. The author analyses how proverbs are exploited in street graffiti and specific poster texts by the Tartu group of the Loesje movement. The paper contains the analysis of "the proportion of traditional and improvisational, local and global in paremia" used in the public space (p. 237). The aim of the article is to give an insight into the linguo-cultural specifics of the research material, which is analysed with a view to determining which attitudes, ideas etc. are reflected in it and how they are communicated. Proverbial elements in graffiti are also discussed by Grzegorz Szpila in his paper Regulating the reality? Proverbs in Polish graffiti (pp. 269-284), which is a valuable contribution to the studies on Polish mural inscriptions. The analysis of paremic mural inscriptions is conducted so that it could be determined whether proverbs are used in Polish grafitti "only as content-free play on traditional folk wisdom" (p. 269). The central point of the paper is the status of anti-proverbs in the Polish public space. The author states that they not only are means of expressing emotional attitudes, but also serve as one of commenting on reality in a way which is not so anti-proverbial as it could be expected. In conclusion, answering the question whether or not they regulate the reality, the authors calls them "new regulators, neoregulators, replacing those proverbs which are no longer applicable and turning others into more apt systematisers of human experience" (p. 282). 
The volume reviewed offers a collection of analyses of various aspect of modern culture of Estonia and Poland, two post-socialist countries, which experienced rapid changes observed in various aspects of life. The changes are reflected in many ways in language and it is worth analysing how it is done, especially - as it is in this case - in a cross-cultural perspective, to determine the differences and to find the similarities. The idea of presenting selected issues in a series parallel articles allows for perfect comparison of the issues discussed and constitutes a model of how contrastive research can be presented. It facilitates observing what is shared in the way given phenomena developed in the two cultures.

The articles contributed to the volume deal mostly with humour which is presented in various texts of culture. Two other issues, proverbs and online aggressiveness, are also discussed. Thanks to the selection of subjects the whole book offers a panoramic view of similarities and differences in cultural phenomena in Estonia and Poland, showing how political and economic changes influenced them. The volume is highly recommended for those who are interested in linguo-cultural studies, especially in humour, media texts and on-line communication. To sum up, it can be concluded that it is a valuable publication because of many reasons: the choice of the topics discussed, so relevant in the modern world, the level of the papers which give an insight into the matters discussed, and the idea of structuring the volume into sections containing two articles each, a model to be followed, and careful editing. The book is inspiring and thought-provoking, not only providing information, but also setting the paths for further research in the field of humour and related issues. 